Case report

\title{
Pneumonia as a trigger for atrial fibrillation
}

\author{
Larry Nichols ${ }^{1}$ \\ ${ }^{I}$ Department of Pathology, Mercer University School of Medicine, USA
}

\begin{abstract}
In a rural mountainous region on a Friday, a 78-year-old man was seen in his physician's office for leg edema and diagnosed with new onset atrial fibrillation. He was discharged home to start medications for atrial fibrillation and heart failure. He was hospitalized the next day with septic shock due to pneumococcal pneumonia. The new onset of atrial fibrillation requires a trigger acting on a vulnerable substrate. These triggers include acute conditions such as alcohol intoxication, myocardial infarction and pulmonary embolism. Pneumonia may act as a trigger causing the new onset of atrial fibrillation.
\end{abstract}

Key words: atrial fibrillation, pneumonia, diagnostic error, rural medicine

(J Rural Med 2017; 12(2): 146-148)

\section{Introduction}

Aging rural populations suffer a large increasing burden of atrial fibrillation (AF). Aging is associated with a dramatic increase in the incidence of AF. The incidence increases from less than $1 \%$ among 60 - to 65 -year-olds to $8 \%$ to $10 \%$ of those over age 85 years $^{1}$. Rural areas have a more aged population. The incidence of AF is increasing worldwide ${ }^{2,3}$. This is a burden because AF causes morbidity, worsening heart failure, for instance, and mortality, especially from thromboembolic stroke ${ }^{1)}$.

The new onset of $\mathrm{AF}$ requires a trigger acting on a vulnerable atrial substrate ${ }^{4}$. Triggers for the new onset of

Received: June 2, 2017

Accepted: July 20, 2017

Correspondence: Larry Nichols, MD, Department of Pathology, Mercer University School of Medicine, 1501 Mercer University Drive, Macon, Georgia 31207-001, USA

E-mail: Nichols_1@mercer.edu

This is an open-access article distributed under the terms of the Creative Commons Attribution Non-Commercial No Derivatives (by-nc-nd) License $<$ http://creativecommons.org/licenses/by-nc-nd/4.0/>.
AF include acute alcohol intoxication ("holiday heart syndrome"), acute myocardial infarction, acute myocarditis, acute pulmonary embolism and acute pulmonary disease in general ${ }^{5}$. Pneumonia appeared on lists of causes of AF in textbooks many years ago, but deserves recognition as a trigger of $\mathrm{AF}$ because $\mathrm{AF}$ arising in this context may resolve with treatment of the acute condition ${ }^{4}$. Furthermore, treatment of the AF without treatment of pneumonia triggering it could enable the pneumonia to be fatal. The following case is reported to bring up these issues.

\section{Case Report}

In a rural mountainous region on a Friday in mid-winter, day 1, a 78-year-old man was seen in his physician's office for a chief complaint of leg edema. The leg swelling had begun the day before. The patient had a past medical history of a ruptured abdominal aortic aneurysm repaired with an aorto-bi-iliac graft, one year prior. He had a history of smoking ending 40 years prior. He was widowed and was a retired public school employee. New onset AF was diagnosed. The patient was discharged home with prescriptions for warfarin, digoxin, and diuretic therapy.

The patient was brought to a local hospital emergency room the following day, day 2, with a one-day history of shortness of breath, two days of leg edema, one week of a nonproductive cough, and three weeks of malaise, fatigue and weakness. He denied fever, chills or sweats.

In the emergency room, the patient's temperature was $36.8^{\circ} \mathrm{C}$, pulse $132 /$ minute, blood pressure (BP) $105 / 56$ $\mathrm{mmHg}$ and respirations 28/minute. He had jugular venous distension, an irregularly irregular pulse, left-sided rhonchi and bibasilar pulmonary crackles. Chest x-ray showed a left lower pulmonary infiltrate, left pleural effusion and cardiomegaly. Electrocardiogram showed AF and no ischemic changes. Creatine phosphokinase was 2205 U/L, AST 128 U/L, LDH $528 \mathrm{U} / \mathrm{L}$, WBC 12,400/cu mm (62\% segmented neutrophils, $22 \%$ bands, $10 \%$ lymphocytes, $4 \%$ monocytes), $\mathrm{Hb} 11.8 \mathrm{~g} / \mathrm{dL}$, and Plts 447,000/cu mm. An arterial blood 
sample showed: $\mathrm{pH}$ 7.37, $\mathrm{pCO}_{2} 19 \mathrm{~mm} \mathrm{Hg}$ and $\mathrm{pO}_{2} 69 \mathrm{~mm}$ $\mathrm{Hg}$. The patient was treated with an infusion of dopamine, diltiazem therapy, intravenous furosemide and intravenous heparin. He became acutely unstable and was intubated; he was then transferred to a referral hospital by helicopter.

On admission at the referral hospital, the patient was unresponsive, with cold mottled skin. His temperature was $36.6^{\circ} \mathrm{C}$, heart rate 108 /minute, respiratory rate $15 /$ minute (on ventilator) and BP $88 / 47 \mathrm{mmHg}$. He had bilateral pulmonary crackles. The heart had an irregular rhythm with no murmurs or gallops. There was mild edema of the lower extremities up to the knees and no pulses palpable distal to the femoral pulses.

Arterial blood showed: $\mathrm{pH} 7.26, \mathrm{pCO}_{2} 26 \mathrm{~mm} \mathrm{Hg}, \mathrm{pO}_{2}$ $299 \mathrm{~mm} \mathrm{Hg}$, lactate $6.9 \mathrm{mEq} / \mathrm{L}$ and glucose $65 \mathrm{mg} / \mathrm{dL}$. Creatinine was $7.1 \mathrm{mg} / \mathrm{dL}$. Chest x-ray showed a left lower lobe infiltrate, a left pleural effusion, and right mid and upper zone infiltrates. An infusion of dobutamine was added to the infusion of dopamine. Empirical antibiotic therapy was started with gentamicin and ticarcillin/clavulanate. Right heart catheterization showed a central venous pressure of $7 \mathrm{~mm} \mathrm{Hg}$, pulmonary artery pressure of $32 / 21 \mathrm{~mm} \mathrm{Hg}$ and pulmonary artery wedge pressure of $19 \mathrm{~mm} \mathrm{Hg}$. Echocardiogram showed moderately decreased left ventricular function and unremarkable cardiac valves.

The following morning, day 3 , the patient remained hypotensive, despite vasopressor therapy, with multi-organ failure, and he died. Blood cultures obtained on admission to the referral hospital yielded Streptococcus pneumoniae.

Autopsy revealed a near-lobar early organizing pneumonia of the lower left lobe, with an associated $700 \mathrm{ml}$ empyema. This pneumonia had the gross and microscopic features of the gray hepatization stage of a pneumococcal pneumonia 4 to 7 days old. Autopsy also demonstrated severe coronary and systemic atherosclerosis, with near-total old occlusion of the left anterior descending and left circumflex coronary arteries, as well as two small old myocardial infarctions in the left ventricle, measuring $2.2 \times 1.8 \times 0.3 \mathrm{~cm}$ and $1.5 \times 0.6 \times 0.3 \mathrm{~cm}$. The abdominal aortic graft showed mild stenosis of the proximal anastomosis, with severe atherosclerosis of the remainder of the aorta.

\section{Discussion}

One might consider whether heart failure was the trigger of AF in this case. The day before the patient died, heart failure was demonstrated by echocardiogram showing moderately decreased left ventricular function and right heart catheterization showing an elevated pulmonary artery wedge pressure. Heart failure was presumably the cause of the leg edema with which he presented, 2 days antemortem, but he had a cough symptomatic of pneumonia for approximately 7 days when he had leg edema for only 2 days. Furthermore, the autopsy showed pneumonia a number of days older than the leg edema. The clinical history fits with septic shock due to the pneumonia. All of this suggests that the pneumonia caused the heart failure and triggered the AF. In general, heart failure is not usually recognized as a cause or trigger of AF. Most authors are careful to describe heart failure as an epidemiologic risk factor, a statistical association or a co-morbidity of $\mathrm{AF}$, but not a cause ${ }^{4,6,7)}$. A recent study documented the new onset of AF in $10.7 \%$ of intensive care unit admissions ${ }^{8}$. Advanced age, acute respiratory failure, and sepsis were the strongest predictors of new-onset $\mathrm{AF}$ in this study ${ }^{8}$. This case report suggests that pneumonia can trigger the new onset of AF even before it causes sepsis and acute respiratory failure. The pathophysiological mechanism could be a cytokine-mediated vasoconstriction creating ischemia at the pulmonary venous atrial interface where AF often originates.

This patient's presentation with new onset AF was associated with a delay in the diagnosis of his pneumonia. It is worth speculating why the diagnosis of pneumonia was not made initially in his primary care physician's office. The rural setting may have been a factor. There is a worldwide shortage of healthcare providers in rural areas. Approximately $50 \%$ of the world's population is in rural areas, bur less than $25 \%$ of physicians provide medical services in rural communities ${ }^{9}$. The smaller the rural community, the longer the hours worked by primary care physicians and the more they work after hours and on-call ${ }^{10)}$. The less time and resources for seeing each patient, the more difficult it becomes to make complete and accurate diagnoses ${ }^{11)}$. The patient's presentation on a Friday may have been a factor if the nearest 24-hour hospital emergency department was at a great distance and the primary care physician's office had limited or no weekend hours so that more patients sought care for subacute and chronic complaints, making less time for the ones with truly acute serious conditions.

The patient had no fever the following day and presumably had no fever on his presentation as an outpatient, so this strong clinical clue to infection was absent, as it often is in elderly patients. Fever is absent in 30 to $40 \%$ of older adult patients with pneumonia ${ }^{12}$. The patient may have had bibasilar pulmonary crackles from heart failure obscuring the findings of his unilateral lower lobe pneumonia. Once the diagnosis of new onset AF was made, the physician may have made the diagnostic error of anchoring, dropping anchor too soon before entering all the way into the harbor of full and accurate diagnosis ${ }^{13}$. The most frequently missed diagnosis in one study of diagnostic errors in an ambulatory primary care setting was pneumonia ${ }^{11)}$. Perhaps the most 
important lesson from this case is to look for pneumonia in elderly patients who suffer the new onset of AF.

\section{References}

1. Zimetbaum P. Atrial Fibrillation. Ann Intern Med 2017; 166: ITC33-ITC48. [Medline] [CrossRef]

2. Lane DA, Skjøth F, Lip GYH, et al. Temporal trends in incidence, prevalence, and mortality of atrial fibrillation in primary care. J Am Heart Assoc 2017; 6: e005155. [Medline] [CrossRef]

3. Bai Y, Wang YL, Shantsila A, et al. The global burden of atrial fibrillation and stroke: a systematic review of the clinical epidemiology of atrial fibrillation in Asia. Chest 2017; pii: S0012-3692(17)30721-3. [Medline]

4. Staerk L, Sherer JA, Ko D, et al. Atrial fibrillation: epidemiology, pathophysiology, and clinical outcomes. Circ Res 2017; 120: 1501-1517. [Medline] [CrossRef]

5. Levy S. Atrial fibrillation, the arrhythmia of the elderly, causes and associated conditions. Anadolu Kardiyol Derg 2002; 2: 55-60. [Medline]

6. Yamauchi T, Sakata Y, Miura M, et al. CHART-2 Investigators. Prognostic impact of atrial fibrillation and new risk score of its onset in patients at high risk of heart failure - a report from the CHART-2 study. Circ J 2017; 81: 185-194. [Medline] [CrossRef]
7. Patel RB, Vaduganathan M, Shah SJ, et al. Atrial fibrillation in heart failure with preserved ejection fraction: Insights into mechanisms and therapeutics. Pharmacol Ther 2016 pii: S0163-7258(16)30198-X. [Medline]

8. Moss TJ, Calland JF, Enfield KB, et al. New-onset atrial fibrillation in the critically ill. Crit Care Med 2017; 45: 790-797. [Medline] [CrossRef]

9. Budhathoki SS, Zwanikken PA, Pokharel PK, et al. Factors influencing medical students motivation to practise in rural areas in low-income and middle-income countries: a systematic review. BMJ Open 2017; 7: e013501. [Medline] [CrossRef]

10. McGrail MR, Humphreys JS, Joyce CM, et al. How do rural GPs workloads and work activities differ with community size compared with metropolitan practice? Aust J Prim Health 2012; 18: 228-233. [Medline] [CrossRef]

11. Singh H, Giardina TD, Meyer AN, et al. Types and origins of diagnostic errors in primary care settings. JAMA Intern Med 2013; 173: 418-425. [Medline] [CrossRef]

12. Torres A, Menéndez R, Wunderink RG. Bacterial pneumonia and lung abscess. In: Murray \& Nadel's Textbook of Respiratory Medicine. 6th ed. Broaddus VC, Ed. Elsevier, Philadelphia 2016; 1: 557-582.

13. Mull N, Reilly JB, Myers JS. An elderly woman with heart failure: cognitive biases and diagnostic error. Cleve Clin J Med 2015; 82: 745-753. [Medline] [CrossRef] 